\title{
In vitro evidence of the role of hemoglobin during vasospasm on the modifications of the expression of PKC $\alpha$ and $\xi$
}

\author{
FLORENCE LEFRANC $^{1,2}$, BORIS LUBICZ ${ }^{3}$ and OLIVIER DEWITTE ${ }^{1}$ \\ ${ }^{1}$ Department of Neurosurgery, Erasme University Hospital, Brussels; ${ }^{2}$ Laboratory of Toxicology, Institute of Pharmacology, \\ Université Libre de Bruxelles, Brussels; ${ }^{3}$ Department of Radiology, Erasme University Hospital, Brussels, Belgium
}

Received May 30, 2007; Accepted July 2, 2007

\begin{abstract}
The cellular events leading to cerebral vasospasm after subarachnoid hemorrhage (SAH) are poorly understood, although the family of protein kinase $\mathrm{C}$ (PKC) is already known to play crucial roles in this pathology. Hemoglobin $(\mathrm{Hb})$ is one of the major causes of the cerebral vasospasm that follows SAH. In the present study we investigated whether $\mathrm{Hb}$ can in vitro regulate $\mathrm{PKC}$ expression in endothelial as opposed to smooth-muscle cells. The levels of expression of $\mathrm{PKC} \alpha$ and $\mathrm{PKC} \zeta$ were quantitatively determined by means of computer-assisted fluorescence microscopy in the A7r5 smooth-muscle rat cells and human umbilical endothelial cells (HUVECs). Hb significantly modified both calciumdependent $\mathrm{PKC} \alpha$ and calcium-independent $\mathrm{PKC} \zeta$ expression in HUVECs and A7r5 smooth-muscle rat cells. Our data showed that, in vitro, $\mathrm{Hb}$ promptly and markedly modified the levels of expression of both calcium-dependent PKC $\alpha$ and calcium-independent $\mathrm{PKC} \zeta$. We are currently investigating the effects of specific PKC antagonists associated or not with calcium channel blockers on the expression of PKC and the in vivo severity of $\mathrm{SAH}$-induced vasospasm. Our results encourage the prophylactic use of specific PKC isoform antagonists associated with calcium channel blockers early after SAH to prevent cerebral vasospasm.
\end{abstract}

\section{Introduction}

Subarachnoid hemorrhage ( $\mathrm{SAH})$ is a unique disorder and a major clinical problem that most commonly occurs when an aneurysm in a cerebral artery ruptures and causes bleeding

Correspondence to: Dr Florence Lefranc, Laboratory of Toxicology, Institute of Pharmacology, Université Libre de Bruxelles, Campus de la Plaine CP205/1, Boulevard du Triomphe, 1050 Brussels, Belgium

E-mail: fllefran@ulb.ac.be

Key words: in vitro vasospasm, human umbilical endothelial cells, A7r5 smooth-muscle cells, protein kinase C, computer-assisted fluorescence microscopy, hemoglobin and clot formation (1). Despite advances in the treatment of aneurysmal SAH, cerebral vasospasm remains a common complication and has been correlated with a 1.5- to 3-fold increase in death during the first 2 weeks after hemorrhage (2). A number of medical, pharmacological, and surgical therapies are currently in use or being investigated in an attempt to reverse cerebral vasospasm, but only a few have proven to be useful (2).

Two major mechanisms concur to cause cerebral vasospasm after $\mathrm{SAH}$, i.e. first, activation of calciumcalmodulin-dependent protein kinases, and second, the increase in protein kinase $\mathrm{C}$ (PKC) (3-11). Whereas the first mechanism leads to a transient contraction, most of the experimental results in vitro or in animal models support the view that activation of $\mathrm{PKC}$ in cerebral vasospasm results in a delayed but prolonged contraction of major arteries after SAH (9-11). We have recently shown that SAH-induced vasospasm in rat basilar artery markedly modifies the levels of expression of $\mathrm{PKC} \alpha$ and $\mathrm{PKC} \zeta$, and, to a lesser extent, of $\mathrm{PKC} \beta$ and $\mathrm{PKC} \eta$ in endothelial and smooth-muscle cells (12). While PKC $\alpha$ and $\mathrm{PKC} \beta$ are $\mathrm{Ca}^{2+}$-dependent, $\mathrm{PKC} \eta$ and PKC $\zeta$ are calcium-independent $(13,14)$.

The PKC family consists of at least 12 isoforms with clear differences in structure, substrate requirements, expression and locus $(13,14)$. Differences in their structures and substrate requirements have enabled them to be divided into three groups, namely i) the conventional PKCs (cPKC) $\alpha$ ßI, $\beta I I$ and $\gamma$, which are $\mathrm{Ca}^{2+}$-dependent and activated by both phosphatidylserine (PS) and the second messenger diacylglycerol (DAG); ii) the novel PKCs (nPKC) $\delta, \varepsilon, \eta$ and $\theta$, which are $\mathrm{Ca}^{2+}$-independent and regulated by PS and DAG; and iii) the atypical PKCs $(\mathrm{aPKC}) \xi$ and $\mathrm{t} / \lambda$, which are $\mathrm{Ca}^{2+}-$ independent and do not require DAG for activation even though PS does regulate their activity $(13,14)$.

Oxyhemoglobin $(\mathrm{oHb})$ is also suspected of being one of the causes of the cerebral vasospasm that follows SAH (15-18). This indicates that endothelin-1 (ET-1), which is a potent vasoconstrictor, can be induced with $\mathrm{Hb}$ in both vascular endothelial and smooth-muscle cells through PKC activation (19). In cerebrovascular smooth muscle, oHb induced Rho and both PKC $\alpha$ and PKC $\varepsilon$ translocation (15), and a threshold concentration of ET-1 potentiated the contraction induced by $\mathrm{oHb}$ via RhoA/Rho kinase- and $\mathrm{PKC} \varepsilon$-dependent mechanisms (20). Moreover, in a canine two-hemorrhage model, PKC and Rho kinase proteins 
interacted in the development of cerebral vasospasm (21). Therefore, we investigated in vitro the influence of hemoglobin on the calcium-dependent PKC $\alpha$ and the calcium-independent $\mathrm{PKC} \zeta$ levels of expression in A7r5 smooth-muscle rat cells and human umbilical endothelial cells (HUVECs).

\section{Materials and methods}

Cell lines and reagents. The A7r5 smooth-muscle cells from thoracic rat aorta from the American Type Culture Collection (ATCC CRL-1444; Manassas, VA) were grown as monolayers cultured at $37^{\circ} \mathrm{C}$ in closed Falcon plastic dishes (Nunc, Life Technologies, Merelbeke, Belgium) containing Eagle's minimum essential medium (MEM, Gibco, Life Technologies), to which $5 \%$ fetal calf serum (FCS; Gibco) was added. The FCS was heat-inactivated for $1 \mathrm{~h}$ at $56^{\circ} \mathrm{C}$. The HUVECs were grown as in vitro monolayers. The monolayers were obtained by means of a method adapted from the procedure described by Gimbrone et al (22) and cultured at $37^{\circ} \mathrm{C}$ in Endothelial Cell Growth Medium 2 (ECGM2, ImTec Diagnostics, Antwerp, Belgium). The same batch of HUVEC primo-culture was used in the present study. All the media were supplemented with a mixture of $0.6 \mathrm{mg} / \mathrm{ml}$ glutamine, $200 \mathrm{IU} / \mathrm{ml}$ penicillin, $200 \mathrm{~g} / \mathrm{ml}$ streptomycin and $0.1 \mathrm{mg} / \mathrm{ml}$ gentamycin (all from Gibco).

The two anti-PKC antibodies were purchased from Santa Cruz Biotechnology (Boechout, Belgium) and used at a dilution $1 / 200$.

\section{Fluorescent detection of protein expression}

Experimental conditions. The levels of PKC $\alpha$ and $\mathrm{PKC} \xi$ expression in the A7r5 and HUVECs were analyzed in the absence (control) or the presence of hemoglobin (with concentrations ranging from $10^{-11} \mathrm{M}$ to $10 \mu \mathrm{M}$ ) for $30 \mathrm{~min}$ and $3 \mathrm{~h}$.

Immunocytochemical procedures. A7r5 and HUVEC suspensions were seeded onto glass coverslips $48 \mathrm{~h}$ prior to the immunofluorescence staining, after which the cells were

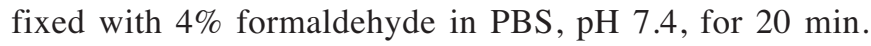
Five coverslips were available for each experimental condition and for each cell line. In order to detect the PKC isoforms, the cells were permeabilized with $0.2 \%$ Triton $\mathrm{X}-100$ for $5 \mathrm{~min}$, and unspecific bounds were blocked for $20 \mathrm{~min}$ with $1 \%$ horse serum (Vector Laboratories; Burlingame, CA). The binding of the primary antibodies was detected by Alexa Fluor-594-conjugated secondary antibody $(10 \mu \mathrm{g} / \mathrm{ml}$; Molecular Probes, Invitrogen, Merelbeke, Belgium).

Computer-assisted microscopy. The level of expression of each PKC isotype (relating to the intensity of the fluorescence staining) was quantitatively determined by means of computerassisted fluorescence microscopy using a Provis Olympus Microscope (Omnilabo S.A., Antwerp, Belgium) coupled to a Megaview 2 camera (Omnilabo S.A.) feeding digitized information into a computer using an AnalySIS ${ }^{\circledR}$ software (Soft Imaging System, GmbH, Munster, Germany). Five hundred cells were analyzed per cell line for PKC $\alpha$ and $\mathrm{PKC} \zeta$ in each of the experimental conditions under study.
Data analysis. All the values shown are the means \pm standard error (SEM). All the statistical analyses were carried out using Statistica (Statsoft, Tulsa, Oklaoma). The statistical significance of the comparisons between the different experimental conditions was tested by the non-parametric Mann-Whitney $U$ test and is indicated by ${ }^{*} \mathrm{p}<0.05,{ }^{* *} \mathrm{p}<0.01$, and ${ }^{* * *} \mathrm{p}<0.001$.

\section{Results}

In vitro characterization of hemoglobin $(\mathrm{Hb})$-induced modifications to the expression of the calcium-dependent $c P K C \alpha$ and the calcium-independent $a P K C \zeta$ in smoothmuscle and endothelial cells. The influence of the $\mathrm{Hb}$-induced effects on $\mathrm{PKC} \alpha$ and $\mathrm{PKC} \zeta$ expression was determined $30 \mathrm{~min}$ and $3 \mathrm{~h}$ after its addition to the culture medium. Fig. 1A illustrates the influence of $\mathrm{Hb}$-induced effects on PKC $\alpha$ expression in HUVECs 30 min after its addition to the culture medium. The data show that $30 \mathrm{~min}$ after addition of $\mathrm{Hb}$, the levels of PKC $\alpha$ were markedly decreased for $\mathrm{Hb}$ concentrations ranging from $10^{-11}$ to $10^{-9} \mathrm{M}$ (Fig. 1A). These marked effects vanished almost completely $3 \mathrm{~h}$ after $\mathrm{Hb}$ addition to the HUVEC culture medium (data not shown). In sharp contrast to what was observed concerning the negative influence of $\mathrm{Hb}$ on the expression of PKC $\alpha$ in the HUVECs (Fig. 1A), Hb stimulated the expression of $\mathrm{PKC} \zeta$ in these cells in doses ranging from $10^{-10}$ to $10^{-8} \mathrm{M}, 3 \mathrm{~h}$ after its addition to the culture medium (Fig. 1B). No statistically significant influence was observed $30 \mathrm{~min}$ after its addition to the culture medium (data not shown).

Fig. 1C and D give morphological illustrations of PKC $\alpha$ expression in the control HUVECs as opposed to the HUVECs cultured for $30 \mathrm{~min}$ in the presence of $10^{-10} \mathrm{M} \mathrm{Hb}$.

No statistically significant $\mathrm{Hb}$-induced modifications to the PKC $\alpha$ expression were observed in the A7r5 cells 30 min after the addition of $\mathrm{Hb}$ to the culture medium (data not shown). Hb significantly decreased the PKC $\zeta$ expression in the A7r5 cells $3 \mathrm{~h}$ after its addition to the culture medium (Fig. 2B). We observed no statistically significant effects of $\mathrm{Hb}$ on $\mathrm{PKC} \zeta$ expression in the A7r5 cells 30 min after its addition to the culture medium (data not shown). Fig. $2 \mathrm{C}$ and $\mathrm{D}$ illustrate the morphological patterns of $\mathrm{PKC} \zeta$ expression in the A7r5 control cells as opposed to the A7r5 cells cultured for $3 \mathrm{~h}$ in the presence of $10^{-9} \mathrm{M} \mathrm{Hb}$.

\section{Discussion}

Over the past decade a variety of molecular mechanisms have been explored and a number of mediators including endothelium-derived mediators (nitric oxide, oxygen-free radicals, endothelin, lipooxygenases, and cyclooxygenases and their metabolites) $(3,4)$; vascular smooth-muscle-derived mediators [potassium channel inhibition, calcium channel activation, reduction in second messengers (cAMP and cGMP), PKC activation] $(3,4)$; pro-inflammatory mediators involved in blood-brain barrier disruption (serotonin, histamine and bradykinin), cytokines (IL-1, TNF- $\alpha$ and IL-6), and adhesion molecules (23); and stress-induced gene activation (heat shock proteins and hemeoxygenase-1) $(3,4,24)$ have been implicated in $\mathrm{SAH}$-induced vasospasm 
HUVEC-1: PKC-alpha
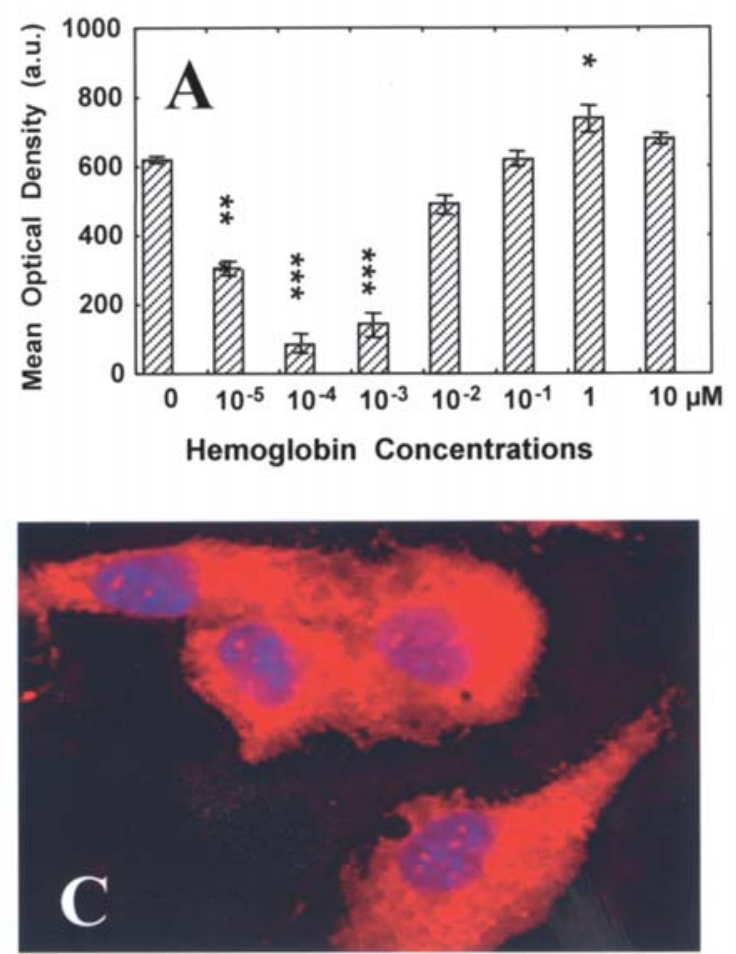

HUVEC-1: PKC-zeta
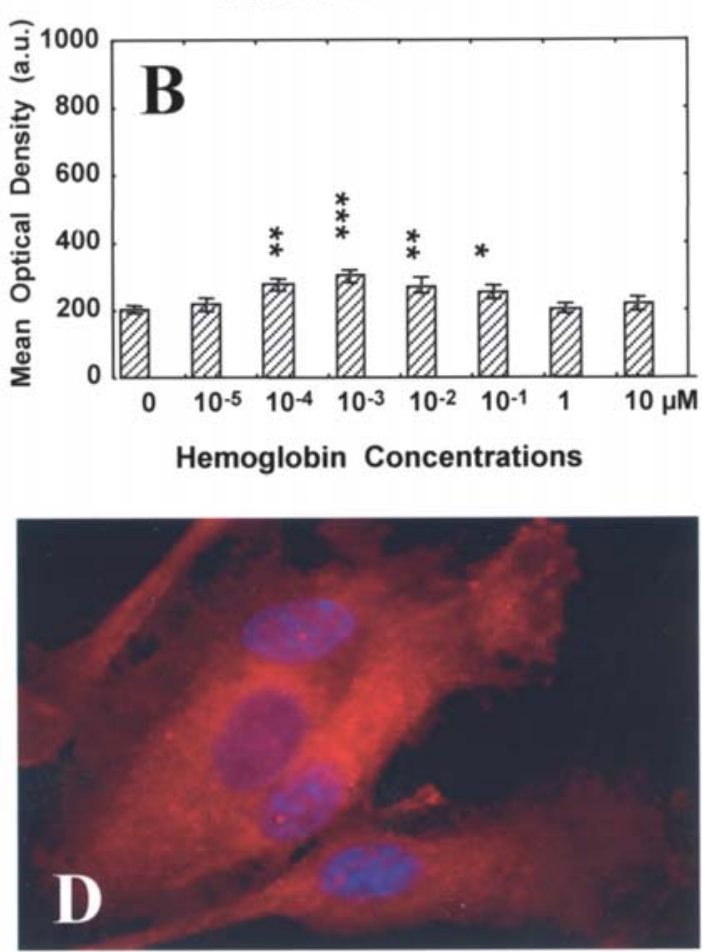

Figure 1. Quantitative determination (by means of computer-assisted fluorescence microscopy) of PKC $\alpha$ (A) and PKC $\zeta$ (B) expression in HUVECs cultured with $\mathrm{Hb}$ concentrations ranging from $10^{-11}$ to $10^{-5} \mathrm{M}$ (control, $0 \mathrm{M}$ ). (A) The influence of the Hb-induced effects on PKC $\alpha$ expression was determined 30 min after the addition of $\mathrm{Hb}$ to the culture medium. (B) The effects of $\mathrm{Hb}$ on PKC 5 expression were determined $3 \mathrm{~h}$ after its addition to the culture medium. (C,D) Morphological illustrations of the PKC $\alpha$ expression in control HUVECs as opposed to HUVECs cultured for 30 min in the presence of $10^{-10} \mathrm{M}$ Hb. The data are presented as the means \pm SEM. The levels of statistical significance; ${ }^{*} \mathrm{p}<0.05,{ }^{* *} \mathrm{p}<0.01$ and ${ }^{* * *} \mathrm{p}<0.001$.

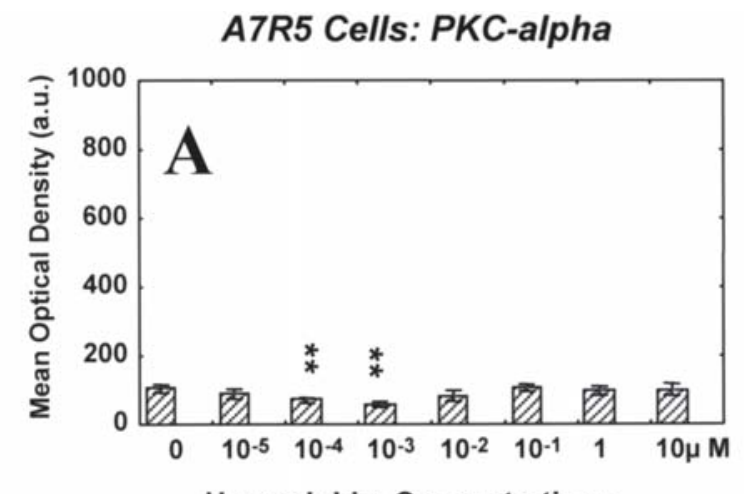

Hemoglobin Concentrations

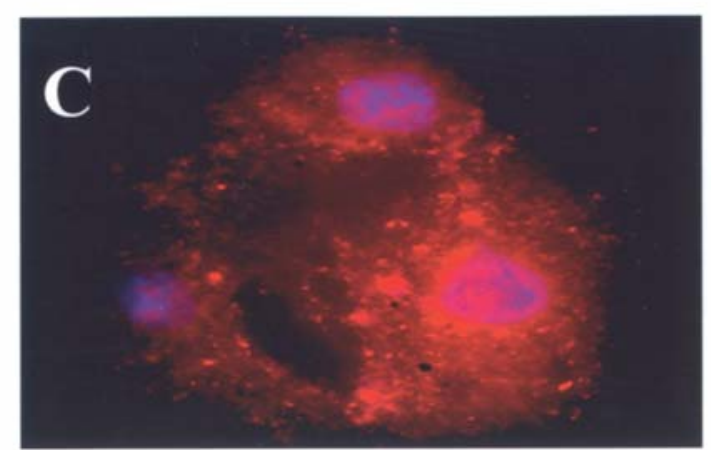

A7R5 Cells: PKC-zeta

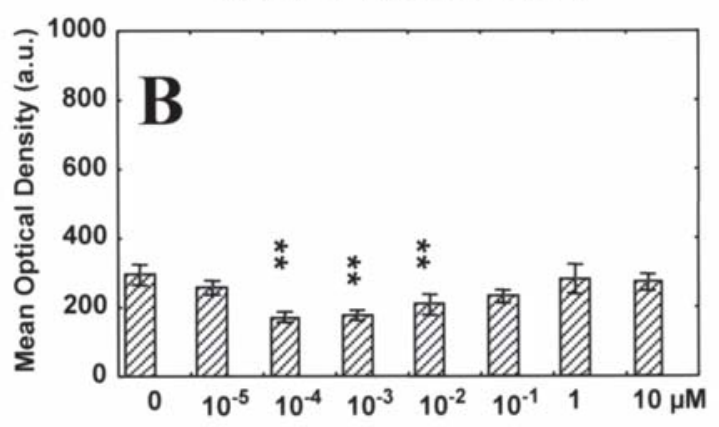

Hemoglobin Concentrations

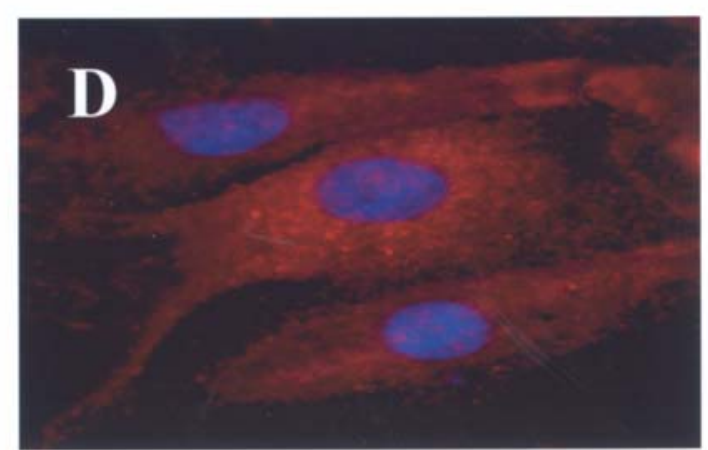

Figure 2. Quantitative determination (by means of computer-assisted fluorescence microscopy) of PKC $\alpha$ (A) and PKC $\zeta$ (B) expression in A7r5 smoothmuscle rat cells cultured with $\mathrm{Hb}$ concentrations ranging from $10^{-11}$ to $10^{-5} \mathrm{M}$ (control, $\left.0 \mu \mathrm{M}\right)$. (A,B) The $\mathrm{Hb}$-induced effects on $\mathrm{PKC} \alpha(2 \mathrm{~A})$ and $\mathrm{PKC} \zeta(\mathrm{B})$ expression in A7r5 smooth-muscle rat cells $3 \mathrm{~h}$ after its addition to the culture medium. (C,D) The morphological patterns of PKC $\zeta$ expression in the A7r5 control cells as opposed to the A7r5 cells cultured for $3 \mathrm{~h}$ in the presence of $10^{-9} \mathrm{M} \mathrm{Hb}$. The data are presented as the means \pm SEM. The level of statistical significance, ${ }^{* *} \mathrm{p}<0.01$. 
pathogenesis. Thus, PKC seems to be a key in cerebral vasospasm. PKC plays a role in the regulation of myogenic tone by sensitization of myofilaments to calcium (9). PKC phosphorylates various ion channels including augmenting voltage-dependent $\mathrm{Ca}^{2+}$ channels and inhibiting $\mathrm{K}^{+}$channels, which both lead to vessel contraction (9). Many signaling pathways interact with PKC activities during vasospasm (10). These factors include nitric oxide (NO) and cGMP, ET-1 and potassium channels $(3,4,25)$ and Rho kinase $(21,26)$. The rise in the intracellular diacylglycerol level causes PKC activation in spastic cerebral arteries, presumably because of the overexpression of ET-1 as well as the generation of free radicals; at the same time the cGMP level is inversely reduced owing to the inactivation of soluble guanylate cyclase by means of some as yet unknown mechanism $(3,4,18)$. In fact, whereas NO induces vascular relaxation by inhibiting PKC activity $(3,4,27)$, SAH impairs this inhibition causing PKC-dependent vascular contraction, such as vasospasm $(27,28)$. Our previous results (12) have shown that, in vivo, SAH-induced vasospasm in rat cerebral arteries mainly modifies PKC $\alpha$ expression in smooth-muscle cells and $\mathrm{PKC} \zeta$ expression in endothelial cells. These modifications have been observed over an extensive period with respect to the potential role of $\mathrm{Hb}$ in $\mathrm{PKC}$ expression following $\mathrm{SAH}$-induced vasospasm since the quantitative determination of PKC expression was carried out $24 \mathrm{~h}$ after the second cisternal injection of autologous blood. In the current series of in vitro experiments and with the goal of pinpointing early molecular events, we investigated the early effects of $\mathrm{Hb}$ on calcium-dependent $\mathrm{PKC} \alpha$ and calciumindependent PKC $\zeta$ expression in HUVECs and A7r5 smoothmuscle rat cells. Our results showed that the levels of both calcium-dependent and calcium-independent PKC expression were promptly modified when $\mathrm{Hb}$ was added to the culture medium of both endothelial and smooth-muscle cells, consistent with an early modification of PKC expression after $\mathrm{SAH}$.

The treatment of patients with vasospasm remains a challenge in clinical practice (2). At present, the mainstay of treatment of cerebral vasospasm includes triple-H (hypervolemia, hemodilution, and hypertension) therapy and oral administration of nimodipine and intracranial angioplasty (2). Nimodipine, the most widely administered calcium channel blocker, was introduced as a therapeutic agent for the prophylaxis of vasospasm based on findings of a small randomized clinical trial in the US (29) and a large clinical trial in the UK (30). Both trials revealed modest improvements in neurological outcomes following nimodipine administration. In a metaanalysis of nimodipine treatment after $\mathrm{SAH}$, Barker and Ogilvy (31) demonstrated that the prophylactic use of this drug is effective in increasing the odds of a good outcome after SAH. Although the drug is accepted as the standard of care, the mechanism by which it works remains controversial (32). Rinkel and colleagues (33) examined the efficacy of calcium antagonists from 12 different trials in a systematic review. The use of calcium antagonists was associated with improved outcomes, but, although calcium channel blockers significantly diminished the rate of secondary ischemia after aneurysmal SAH (from 40 to $27 \%$ ), their use did not reduce the high mortality rate associated with SAH. Our study shows that, in vitro, $\mathrm{Hb}$ markedly and promptly modifies the levels of expression of calcium-dependent PKC $\alpha$ and also calcium-independent $\mathrm{PKC} \xi$. Our results encourage the prophylactic use of specific PKC isoform antagonists associated with nimodipine in cerebral vasospasm trials. Because cerebrospinal fluid (CSF) from SAH patients with cerebral vasospasm accumulates various components like NO, endothelin-1, transferin, bilirubin, bilirubin oxidation products, heme oxygenase and peroxidized lipids (34) which are directly involved in cerebral vasospasm following $\mathrm{SAH}$, we are now investigating the effects of CSF on PKC levels of expression. We also intend to investigate the effects of specific PKC antagonists associated or not with calcium channel blockers on the expression of PKC and the in vivo severity of $\mathrm{SAH}$-induced vasospasm.

\section{Acknowledgements}

We are deeply indebted to Dr J.B. Parys (Laboratory of Physiology, Katholieke Universiteit Leuven, Belgium) for providing us with vials of A7r5 smooth-muscle cells taken from thoracic rat aorta. F.L. is a Clinical Research Fellow with the Fonds National de la Recherche Scientifique (FNRS, Belgium).

\section{References}

1. van Gijn J and Rinkel GJE: Subarachnoid haemorrhage: diagnosis, causes and management. Brain 124: 249-278, 2001.

2. Mocco J, Zacharia BE, Komotar RJ and Connolly ES Jr: A review of current and future medical therapies for cerebral vasospasm following aneurismal subarachnoid hemorrhage. Neurosurg Focus 21: E9, 2006.

3. Dietrich HH and Dacey RG: Molecular keys to the problems of cerebral vasospasm. Neurosurgery 46: 517-530, 2000.

4. Pasqualin A: Epidemiology and pathophysiology of cerebral vasospasm following subarachnoid haemorrhage. J Neurosurg Sci 42: 15-21, 1998 .

5. Takuwa Y, Matsui T, Abe Y, Nagafuji T, Yamashita K and Asano T: Alterations in protein kinase $\mathrm{C}$ activity and membrane lipid metabolism in cerebral vasospasm after subarachnoid hemorrhage. J Cereb Blood Flow Metab 13: 409-415, 1993.

6. Nishizawa S, Obara K, Nakayama1 K, Koide M, Yokoyama T, Yokota N and Ohta S: Protein kinase C-delta and -alpha are involved in the development of vasospasm after subarachnoid hemorrhage. Eur J Pharmacol 398: 113-119, 2000.

7. Asano $\mathrm{T}$ and Matsui T: Various pathogenetic factors revolving around the central role of protein kinase $\mathrm{C}$ activation in the occurrence of cerebral vasospasm. Crit Rev Neurosurg 8: 176-187, 1998.

8. Kawamata T, Peterson JW, Bun T and Zervas NT: Augmentation of both hemolysate-induced contraction and activation of protein kinase $\mathrm{C}$ by submaximum activation in canine cerebral arteries in vitro. J Neurosurg 87: 908-915, 1997.

9. Laher I and Zhang JH: Protein kinase C and cerebral vasospasm. J Cereb Blood Flow Metab 21: 887-906, 2001.

10. Zhang JH: Role of protein-kinase $C$ in cerebral vasospasm: past and future. Neurol Res 22: 369-378, 2000.

11. Nishizawa S, Obara K, Koide M, Nakayama $K$, Ohta $S$ and Yokoyama T: Attenuation of canine cerebral vasospasm after subarachnoid hemorrhage by protein kinase $\mathrm{C}$ inhibitors despite augmented phosphorylation of myosin light chain. J Vasc Res 40: 169-178, 2003.

12. Lefranc F, Decaestecker C, Brotchi J, Heizmann CW, Dewitte O, Kiss R and Mijatovic T: Co-expression/co-location of S100 proteins (S100B, S100A1 and S100A2) and protein kinase C (PKC-beta, -eta and -zeta) in a rat model of cerebral basilar artery vasospasm. Neuropathol Appl Neurobiol 31: 649-660, 2005.

13. Hofmann J: The potential for isoenzyme-selective modulation of protein kinase C. FASEB J 11: 649-669, 1997. 
14. Way KJ, Chou E and King GL: Identification of PKC-isoformspecific biological actions using pharmacological approaches. TiPS 21: 181-187, 2000.

15. Wickman G, Lan C and Vollrath B: Functional roles of the rho/rho kinase pathway and protein kinase $\mathrm{C}$ in the regulation of cerebrovascular constriction mediated by hemoglobin: relevance to subarachnoid hemorrhage and vasospasm. Circ Res 92: 809-816, 2003. Epub Mar 13, 2003.

16. MacDonald RL and Weir BK: A review of hemoglobin and the pathogenesis of cerebral vasospasm. Stroke 22: 971-982, 1991.

17. Macdonald RL, Weir BK, Marton LS, Zhang ZD, Sajdak M, Johns LM, Kowalczuk A and Borsody M: Role of adenosine 5'triphosphate in vasospasm after subarachnoid hemorrhage: human investigations. Neurosurgery 48: 854-862, 2001.

18. Yin W, Tibbs R, Tang J, Badr A and Zhang J: Haemoglobin and ATP levels in CSF from a dog model of vasospasm. J Clin Neurosci 9: 425-428, 2002.

19. Nishizawa S, Chen D, Yokoyama T, Yokota N and Otha S: Endothelin-1 initiates the development of vasospasm after subarachnoid haemorrhage through protein kinase $\mathrm{C}$ activation, but does not contribute to prolonged vasospasm. Acta Neurochir 142: 1409-1415, 2000.

20. Lan C, Das D, Wloskowicz A and Vollrath B: Endothelin-1 modulates hemoglobin-mediated signaling in cerebrovascular smooth muscle via RhoA/Rho kinase and protein kinase C. Am J Physiol Heart Circ Physiol 286: H165-H173, 2004.

21. Obara K, Nishizawa S, Koide M, Nozawa K, Mitate A, Ishikawa $\mathrm{T}$ and Nakayama K: Interactive role of protein kinase C-delta with rho-kinase in the development of cerebral vasospasm in a canine two-hemorrhage model. J Vasc Res 42: 67-76, 2005. Epub January 3, 2005.

22. Gimbrone MA, Cotran RS and Folkman J: Human vascular endothelial cells in culture: growth and DNA synthesis. J Cell Biol 60: 673-684, 1974.

23. Dumont AS, Dumont RJ, Chow MM, Lin CL, Calisaneller T, Ley KF, Kassell NF and Lee KS: Cerebral vasospasm after subarachnoid hemorrhage: putative role of inflammation. Neurosurgery 53: 123-133; discussion 133-135, 2003.

24. Ono S, Zhang ZD, Marton LS, Yamini B, Windmeyer E, Johns L, Kowalczuk A, Lin G and Macdonald RL: Heme oxygenase- 1 and ferritin are increased in cerebral arteries after subarachnoid hemorrhage in monkeys. J Cereb Blood Flow Metab 20: 1066-1076, 2000.
25. Miao L, Dai Y and Zhang J: Mechanism of RhoA/Rho kinase activation in endothelin-1-induced contraction in rabbit basilar artery. Am J Physiol Heart Circ Physiol 283: H983-H989, 2002.

26. Sobey CG and Faraci FM: Subarachnoid haemorrhage: what happens to the cerebral arteries? Clin Exp Pharmacol Physiol 25: 867-876, 1998.

27. Nishizawa S, Yamamoto S, Yokoyama $T$ and Uemura K: Dysfunction of nitric oxide induces protein kinase $\mathrm{C}$ activation resulting in vasospasm after subarachnoid haemorrhage. Neurol Res 19: 558-562, 1997.

28. Nishizawa S, Yokota N, Yokoyama T and Uemura K: Obligatory roles of protein kinase $\mathrm{C}$ and nitric oxide in the regulation of cerebral vascular tone: an implication of a pathogenesis of vasospasm after subarachnoid haemorrhage. Acta Neurochir 140: 1063-1068, 1998.

29. Allen GS, Ahn HS, Preziosi TJ, Battye R, Boone SC, Boone SC, Chou SN, Kelly DL, Weir BK, Crabbe RA, Lavik PJ, Rosenbloom SB, Dorsey FC, Ingram CR, Mellits DE, Bertsch LA, Boisvert DP, Hundley MB, Johnson RK, Strom JA and Transou CR: Cerebral arterial spasm - a controlled trial of nimodipine in patients with subarachnoid hemorrhage. N Engl J Med 308: 619-624, 1983.

30. Pickard JD, Murray GD, Illingworth R, Shaw MD, Teasdale GM, Foy PM, Humphrey PR, Lang DA, Nelson R, Richards P, et al: Effect of oral nimodipine on cerebral infarction and outcome after subarachnoid haemorrhage: British aneurysm nimodipine trial. BMJ 298: 636-642, 1989.

31. Barker FG II and Ogilvy CS: Efficacy of prophylactic nimodipine for delayed ischemic deficit after subarachnoid hemorrhage: a metaanalysis. J Neurosurg. 84: 405-414, 1996.

32. Mesis RG, Wang H, Lombard FW, Yates R, Vitek MP, Borel CO, Warner DS and Laskowitz DT: Dissociation between vasospasm and functional improvement in a murine model of subarachnoid hemorrhage. Neurosurg Focus 21: E4, 2006.

33. Rinkel GJ, Feigin VL, Algra A, van den Bergh WM, Vermeulen M and van Gijn J: Calcium antagonists for aneurysmal subarachnoid haemorrhage. Cochrane Database Syst Rev CD000277, 2005.

34. Pyne-Geithman GJ, Morgan CJ, Wagner K, Dulaney EM, Carrozzella J, Kanter DS, Zuccarello M and Clark JF: Bilirubin production and oxidation in CSF of patients with cerebral vasospasm after subarachnoid hemorrhage. J Cereb Blood Flow Metab 25: 1070-1077, 2005. 